\title{
Not all 1p/19q non-codeleted oligodendroglial tumors are astrocytic
}

\author{
Yan-Xi Li, ${ }^{1,2,4}{ }^{*}$, Zhifeng Shi ${ }^{4, *}$, Abudumijiti Aibaidula ${ }^{4}$, Hong Chen ${ }^{5}$, Qisheng Tang ${ }^{4}$, \\ Kay Ka-Wai Li' ${ }^{1,2}$, Nellie Yuk-Fei Chung ${ }^{1,2}$, Danny Tat-Ming Chan ${ }^{3}$, Wai Sang Poon ${ }^{3}$, \\ Ying $\mathrm{MaO}^{4}$, Jinsong Wu ${ }^{4}$, Liangfu Zhou ${ }^{4}$, Aden Ka-yin Chan ${ }^{1,2}$ and Ho-Keung $\mathrm{Ng}^{1,2}$ \\ ${ }^{1}$ Department of Anatomical and Cellular Pathology, Chinese University of Hong Kong, Hong Kong, China \\ 2 Shenzhen Research Institute, Chinese University of Hong Kong, Hong Kong, China \\ ${ }^{3}$ Neurosurgery Division, Department of Surgery, Chinese University of Hong Kong, Hong Kong, China \\ ${ }^{4}$ Department of Neurosurgery, Huashan Hospital, Fudan University, Shanghai, China \\ ${ }^{5}$ Department of Neuropathology, Huashan Hospital, Fudan University, Shanghai, China \\ * These authors have contributed equally to this work \\ Correspondence to: Aden Ka-yin Chan, email: adenchan@cuhk.edu.hk \\ Liangfu Zhou, email: Ifzhouc@126.com \\ Keywords: oligodendroglial tumors, intact 1p/19q, TERT, IDH, Pathology Section \\ Received: April 19, $2016 \quad$ Accepted: August 12, $2016 \quad$ Published: August 18, 2016
}

\section{ABSTRACT}

Although 1p/19q codeletion is the genetic hallmark defining oligodendrogliomas, approximately $30-40 \%$ of oligodendroglial tumors have intact $1 \mathrm{p} / 19 \mathrm{q}$ in the literature and they demonstrate a worse prognosis. This group of $1 \mathrm{p} / 19 q$ intact oligodendroglial tumors is frequently suggested to be astrocytic in nature with TP53 and ATRX mutations but actually remains under-investigated. In the present study, we provided evidence that not all 1p/19q intact oligodendroglial tumors are astrocytic through histologic and molecular approaches. We examined 1p/19q status by FISH in a large cohort of 337 oligodendroglial tumors and identified $39.8 \%$ lacking 1p/19q codeletion which was independently associated with poor prognosis. Among this $1 \mathrm{p} / 19 q$ intact oligodendroglial tumor cohort, 58 cases demonstrated classic oligodendroglial histology which showed older patient age, better prognosis, association with grade III histology, PDGFRA expression, TERTp mutation, as well as frequent IDH mutation. More than half of the 1p/19q intact oligodendroglial tumors showed lack of astrocytic defining markers, p53 expression and ATRX loss. TP53 mutational analysis was additionally conducted in 45 cases of the 1p/19q intact oligodendroglial tumors. Wild-type TP53 was detected in $71.1 \%$ of cases which was associated with classic oligodendroglial histology. Importantly, IDH and TERTp co-occurred in $75 \%$ of 1p/19q intact, TP53 wild-type oligodendrogliomas, highlighting the potential of the co-mutations in assisting diagnosis of oligodendrogliomas in tumors with clear cell morphology and non-codeleted 1p/19q status. In summary, our study demonstrated that not all 1p/19q intact oligodendroglial tumors are astrocytic and co-evaluation of IDH and TERTp mutation could potentially serve as an adjunct for diagnosing 1p/19q intact oligodendrogliomas.

\section{INTRODUCTION}

Oligodendroglial tumors comprise of oligodendrogliomas and oligoastrocytomas and are associated with favorable clinical behaviors compared with astrocytomas and some can be chemosensitive [1]. Codeletion of $1 p$ and $19 q$ is a characteristic genetic signature which is observed in 39-70\% of oligodendrogliomas and 21-59\% of oligoastrocytomas in most series [2-4]. Codeletion is associated with longer survival and is also a predictive marker for response to chemotherapy with procarbazine, lomustine and vincristine $[1,5]$.

Aside from codeletion of $1 \mathrm{p} / 19 \mathrm{q}$, oligodendroglial tumors are strongly associated with mutations of $I D H 1 / 2$, 
TERT promoter (TERTp) and they are also associated with methylation of $M G M T$ and upregulation of PDGFRA [6-8]. TERTp mutations are regarded as a common mechanism of upregulation of telomerase in primary glioblastoma and oligodendroglial tumors [9]. 1p/19q codeleted and TERTp mutated tumors are mutually exclusive with tumors exhibiting mutations in $A T R X$ (alpha thalassemia mental retardation syndrome $\mathrm{X}$ linked) and TP53. The latter two are usually regarded as markers of astrocytic lineage [7, 10-12].

The fact remains that in most series with many coming from important international trials, 30-40\% of oligodendroglial tumors are $1 \mathrm{p} / 19 \mathrm{q}$ non-codeleted and these tumors exhibit a worse prognosis [1, 13-15]. It has been proposed that most, if not all, of these non-codeleted tumors are actually astrocytic in nature with either TP53 or ATRX mutations [11]. However, there have been few large-scale studies on molecular characterization of oligodendroglial tumors without $1 \mathrm{p} / 19 \mathrm{q}$ codeletion. They make up a significant proportion of "oligodendroglial tumors" diagnosed in international series and daily practice and there is no standard-of-care treatment strategy. In this study, we aim to characterize the molecular and clinical features of this neglected group, interrogating them with standard biomarkers and correlating with overall survival.

\section{RESULTS}

\section{Cohort characteristics}

The 337 cases of oligodendroglial tumors included 125 oligodendrogliomas (WHO grade II), 105 oligoastrocytomas (WHO grade II), 72 anaplastic oligodendrogliomas (WHO grade III) and 33 anaplastic oligoastrocytomas (WHO grade III). The mean and median ages of the cohort were 43.1 and 43.0 years, respectively (range 5 to 70 years). The male to female ratio was 1:0.77. Operation data was available in $80.9 \%$ $(271 / 335)$ of patients, with $72.7 \%(197 / 271)$ of patients received total resection and $27.3 \%(74 / 271)$ of patients received non-total resection. Adjuvant treatment data was available in $75.8 \%$ (254/335) of patients, with $76 \%$ $(193 / 254)$ of patients receiving radiotherapy and $57.1 \%$ $(145 / 254)$ of patients receiving chemotherapy. Survival data was available in $74.3 \%(249 / 335)$ of patients, with median follow-up and median overall survival being 8.2 years and 10.6 years, respectively. (a)

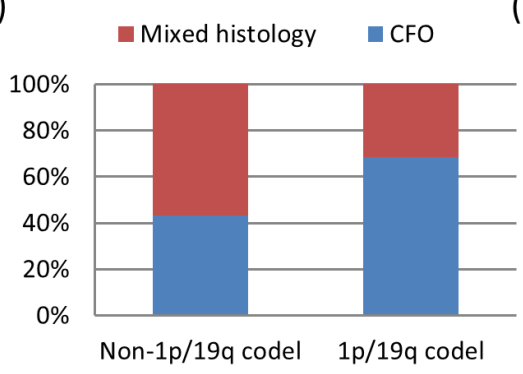

$p<0.00001$ (b)

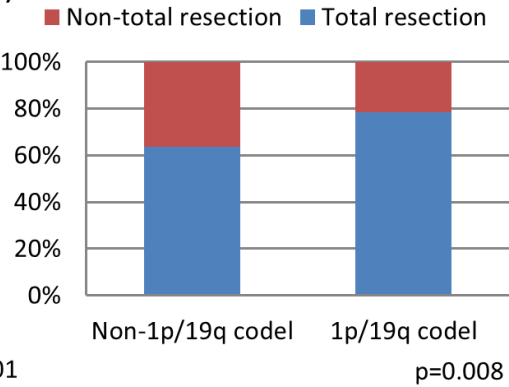

(c)

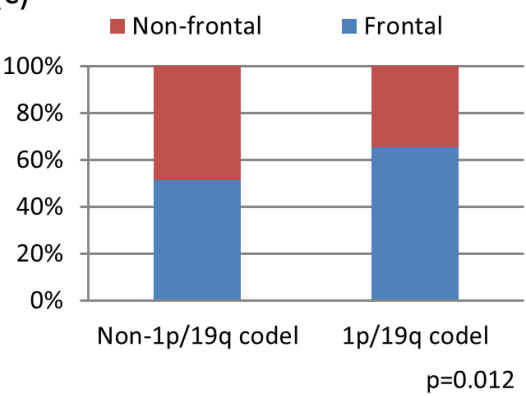

(d)

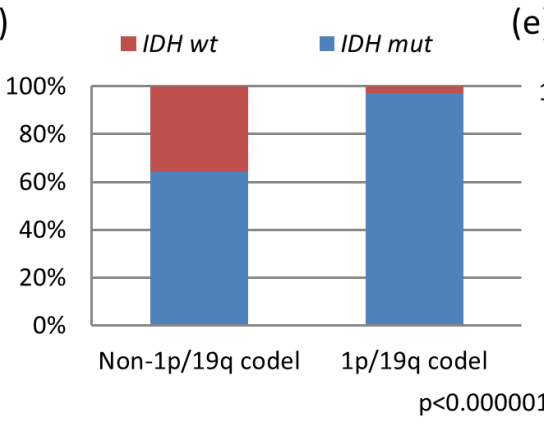

(e)

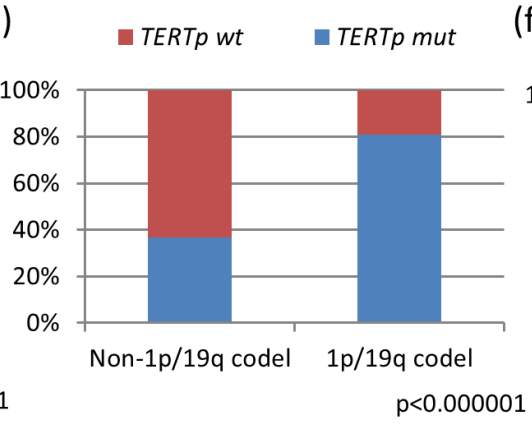

(f)

MGMT unmet $\quad$ MGMT met

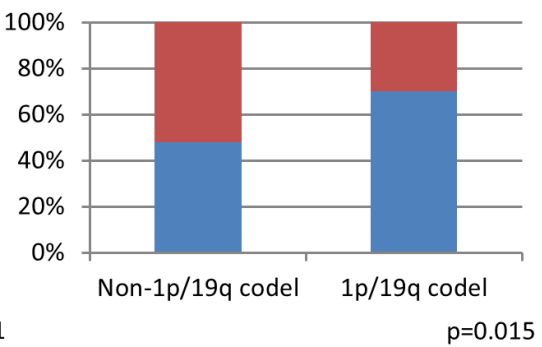

Figure 1: Clinical and molecular characteristics of oligodendroglial tumors based on 1p/19q codeletion status. Tumors with $1 \mathrm{p} / 19 \mathrm{q}$ codeletion showed significant associations with classical oligodendroglial histology $(p<0.00001)$ a. frontal lobe localization $(p=0.012)$ c. and were more amenable to total surgical resection $(p=0.008) \mathbf{b} .1 \mathrm{p} / 19 \mathrm{q}$ codeleted tumors also exhibited co-occurring associations with IDH mutation $(p<0.000001)$ d. TERTp mutation $(p<0.000001)$ e. and $M G M T$ promoter methylation $(p=0.015)$ f. CFO, classic for oligodendroglial morphology; mixed, mixed oligoastrocytic histology; mut, mutant; wt, wild-type; met, methylated; unmet, unmethylated. 


\begin{tabular}{|c|c|c|c|c|c|}
\hline & & n & 1p/19q non-codeleted OTs & 1p/19q codeleted OTs & All OTs \\
\hline \multicolumn{2}{|c|}{ Gender (male / female) } & 337 & $74 / 60$ & $115 / 88$ & $189 / 148$ \\
\hline \multicolumn{2}{|c|}{ Age (mean / median / range) } & 337 & $40.8 / 42 / 5-72$ years & $44.6 / 44 / 21-75$ years & $43.1 / 43 / 5-75$ years \\
\hline \multirow[t]{3}{*}{ Histologic type } & & 337 & & & \\
\hline & Oligodendroglioma & & $58(43.3 \%)$ & $139(68.5 \%)$ & $197(58.5 \%)$ \\
\hline & Oligoastrocytoma & & $76(56.7 \%)$ & $64(31.5 \%)$ & $140(41.5 \%)$ \\
\hline \multirow[t]{3}{*}{ Histologic grade } & & 337 & & & \\
\hline & II & & $86(64.2 \%)$ & $146(71.9 \%)$ & $232(68.8 \%)$ \\
\hline & III & & $48(35.8 \%)$ & $57(28.1 \%)$ & $105(31.2 \%)$ \\
\hline \multirow[t]{7}{*}{ Tumor location } & & 334 & & & \\
\hline & Frontal & & $67(50.8 \%)$ & $126(62.4 \%)$ & $193(57.8 \%)$ \\
\hline & Temporal & & $20(15.2 \%)$ & $23(11.4 \%)$ & $43(12.9 \%)$ \\
\hline & Parietal & & $5(3.8 \%)$ & $11(5.4 \%)$ & $16(4.8 \%)$ \\
\hline & Occipital & & $5(3.8 \%)$ & $3(1.5 \%)$ & $8(2.4 \%)$ \\
\hline & More than one cerebral lobe & & $21(15.9 \%)$ & $27(13.4 \%)$ & $48(14.4 \%)$ \\
\hline & Other locations & & $14(10.6 \%)$ & $12(5.9 \%)$ & $26(7.8 \%)$ \\
\hline \multirow[t]{3}{*}{ Operation } & & 273 & & & \\
\hline & Total resection & & $74(63.8 \%)$ & $123(78.3 \%)$ & $197(72.2 \%)$ \\
\hline & Non-total resection & & $42(36.2 \%)$ & $34(21.7 \%)$ & $76(27.8 \%)$ \\
\hline \multirow[t]{5}{*}{ Adjuvant therapy } & & 256 & & & \\
\hline & Concomitant chemo-radiotherapy & & $47(45.2 \%)$ & $84(55.3 \%)$ & $131(51.2 \%)$ \\
\hline & Radiotherapy only & & $23(22.1 \%)$ & $41(27.0 \%)$ & $64(25.0 \%)$ \\
\hline & Chemotherapy only & & $4(3.8 \%)$ & $9(5.9 \%)$ & $13(5.1 \%)$ \\
\hline & No adjuvant therapy & & $30(28.8 \%)$ & $18(11.8 \%)$ & $48(18.8 \%)$ \\
\hline \multirow[t]{4}{*}{$I D H$} & & 305 & & & \\
\hline & IDH1 mut & & $70(58.3 \%)$ & $172(93.0 \%)$ & $242(79.3 \%)$ \\
\hline & IDH2 mut & & $7(5.8 \%)$ & $8(4.3 \%)$ & $15(4.9 \%)$ \\
\hline & wt & & $43(35.8 \%)$ & $5(2.7 \%)$ & $48(15.7 \%)$ \\
\hline \multirow[t]{4}{*}{ TERTp } & & 248 & & & \\
\hline & $\mathrm{C} 228 \mathrm{~T}$ & & $21(23.3 \%)$ & $91(57.6 \%)$ & $112(45.2 \%)$ \\
\hline & $\mathrm{C} 250 \mathrm{~T}$ & & $12(13.3 \%)$ & $37(23.4 \%)$ & $49(19.8 \%)$ \\
\hline & wt & & $57(63.3 \%)$ & $30(19.0 \%)$ & $87(35.1 \%)$ \\
\hline
\end{tabular}




\begin{tabular}{|c|c|c|c|c|c|c|}
\hline & & n & HR & {$[95 \% \mathrm{CI}]$} & $\begin{array}{|ll|}\begin{array}{l}\text { Median } \\
\text { (years) }\end{array} & \text { OS } \\
\end{array}$ & $p$ \\
\hline \multirow[t]{2}{*}{ Gender } & Male & 137 & 1 & & 10.1 & 0.18 \\
\hline & Female & 106 & 0.755 & {$[0.499-1.141]$} & 11.8 & \\
\hline \multirow[t]{2}{*}{ Age } & $\leq 50$ years & 181 & 1 & & 11.8 & $<0.000001$ \\
\hline & $>50$ years & 62 & 3.289 & {$[2.173-4.98]$} & 5.9 & \\
\hline \multirow[t]{2}{*}{ Histologic grade } & Grade II & 169 & 1 & & 11.8 & $<0.000001$ \\
\hline & Grade III & 74 & 3.84 & {$[2.517-5.859]$} & 6.7 & \\
\hline \multirow[t]{2}{*}{ Histologic type } & Oligodendroglial & 132 & 1 & & 11 & 0.059 \\
\hline & Mixed oligoastrocytic & 111 & 1.481 & {$[0.982-2.234]$} & 10 & \\
\hline \multirow[t]{2}{*}{ Frontal involvement } & Yes & 173 & 1 & & 10.6 & 0.238 \\
\hline & No & 69 & 1.302 & [0.839 - 2.02] & 7.8 & \\
\hline \multirow[t]{2}{*}{ Operation } & Total resection & 173 & 1 & & 11.3 & 0.172 \\
\hline & Non-total resection & 67 & 1.345 & {$[0.878-2.059]$} & 9.7 & \\
\hline \multirow[t]{4}{*}{ Adjuvant therapy } & Concomitant chemo-radiotherapy & 127 & 1 & & 10.6 & 0.361 \\
\hline & Radiotherapy only & 57 & 1.512 & {$[0.867-2.639]$} & 8.8 & \\
\hline & Chemotherapy only & 9 & 1.464 & {$[0.869-2.464]$} & NR & \\
\hline & No adjuvant therapy & 38 & 0.872 & {$[0.21-3.63]$} & 10.1 & \\
\hline \multirow[t]{2}{*}{$1 p / 19 q$} & codeleted & 143 & 1 & & 11.8 & $<0.00001$ \\
\hline & non-codeleted & 100 & 2.563 & [1.689 - 3.889] & 7 & \\
\hline \multirow[t]{2}{*}{$I D H 1 / 2$} & mut & 195 & 1 & & 10.6 & 0.001 \\
\hline & wt & 25 & 2.553 & {$[1.454-4.483]$} & 3.8 & \\
\hline \multirow[t]{2}{*}{ TERTp } & mut & 121 & 1 & & 11.1 & 0.053 \\
\hline & wt & 58 & 1.638 & [0.988 - 2.715] & 10.1 & \\
\hline
\end{tabular}




\begin{tabular}{|c|c|c|c|c|}
\hline & & HR & {$[95 \% \mathrm{CI}]$} & $p$ \\
\hline Age & & 1.074 & {$[1.046-1.103]$} & $<0.000001$ \\
\hline \multirow[t]{2}{*}{ Histologic grade } & Grade II & 1 & & $<0.00001$ \\
\hline & Grade III & 3.736 & [2.087-6.688] & \\
\hline \multirow[t]{2}{*}{ Histologic type } & Oligodendroglial & 1 & & 0.003 \\
\hline & Mixed oligoastrocytic & 2.413 & {$[1.359-4.284]$} & \\
\hline \multirow[t]{2}{*}{$1 \mathrm{p} / 19 \mathrm{q}$} & codeleted & 0.51 & {$[0.296-0.879]$} & 0.015 \\
\hline & non-codeleted & 1 & & \\
\hline \multirow[t]{2}{*}{$I D H 1 / 2$} & mut & 0.364 & {$[0.162-0.817]$} & 0.014 \\
\hline & wt & 1 & & \\
\hline \multirow[t]{2}{*}{ TERTp } & mut & 0.786 & {$[0.441-1.402]$} & 0.415 \\
\hline & wt & 1 & & \\
\hline
\end{tabular}

\section{Clinical and molecular differences between $1 p / 19 q$ codeleted and non-codeleted oligodendroglial tumors}

Chromosomal $1 \mathrm{p}$ and $19 \mathrm{q}$ status were examined in all 337 samples of oligodendroglial tumors, with $1 \mathrm{p}$ loss detected in 63.8\% (215/337) and 19q loss detected in $62.0 \%(209 / 337)$ of the cohort. Combined $1 \mathrm{p} / 19 \mathrm{q}$ codeletion was observed in $60.2 \%$ (203/337) of cases including 95 oligodendrogliomas, 44 anaplastic oligodendrogliomas, 51 oligoastrocytomas and 13 anaplastic oligoastrocytomas. $1 \mathrm{p}$ loss only and $19 \mathrm{q}$ loss only were found in $8.2 \%$ and $4.5 \%$ among the $1341 \mathrm{p} / 19 \mathrm{q}$ non-codeleted oligodendroglial tumors, respectively. Clinical and molecular characteristics were summarized according to $1 \mathrm{p} / 19 \mathrm{q}$ codeletion status in Table 1 . Comparing the variables between $1 \mathrm{p} / 19 \mathrm{q}$ codeleted and non-codeleted oligodendroglial tumors, tumors with codeletion showed significant associations with classic oligodendroglial histology $(p<0.00001)$, frontal lobe localization $(p=0.012)$, and were more amenable to total surgical resection $(p=0.008)$. Molecularly, $1 \mathrm{p} / 19 \mathrm{q}$ codeleted tumors also exhibited co-occurring associations with $I D H$ mutation $(p<0.000001)$, TERTp mutation $(p<$ $0.000001)$, and $M G M T$ promoter methylation $(p=0.015)$ (Figure 1a to 1f).

Univariate survival analysis was conducted in the cohort according to the clinical and molecular variables (Table 2). Oligodendroglial tumors with $1 \mathrm{p} / 19 \mathrm{q}$ codeletion exhibited significantly longer overall survival than $1 \mathrm{p} / 19 \mathrm{q}$ non-codeleted tumors (median OS 11.8 years vs 7.0 years, $p<0.00001)$. Other favorable prognostic factors in univariate analysis included age $\leq 50$ years $(p<0.000001)$, histologic grade II $(p>0.000001)$, and IDH mutation $(p=0.001)$. Trend of better prognosis was observed in tumors with classic oligodendroglial histology $(p=0.059)$ and TERTp mutation $(p=0.053)$. Independent favorable prognostic value of $1 p / 19 q$ codeletion was demonstrated in multivariate analysis by adjusting with significant factors in univariate analysis (Table 3 ). Favorable prognostic value of $1 \mathrm{p} / 19 \mathrm{q}$ codeletion $(\mathrm{HR}=0.51, p=0.015)$ was independent of age $(p<0.000001)$, histologic grade $(p$ $<0.00001)$, histologic type ( $p=0.003), I D H$ status ( $p=$ $0.014)$, and TERTp status $(p=0.415)$. 


\section{Presence of classic oligodendroglial morphology in $1 p / 19 q$ non-codeleted gliomas with distinct features}

Among the 134 cases of $1 \mathrm{p} / 19 \mathrm{q}$ non-codeleted oligodendroglial tumors, $43.3 \%$ (58/134) of cases demonstrated classic oligodendroglial histology, including 30 oligodendrogliomas and 28 anaplastic oligodendrogliomas. Interestingly, patients with classic oligodendroglial histology were significantly older than those with mixed oligoastrocytic histology (mean age 44.5 years vs 38.0 years, $p=0.01$ ) (Figure 2a). The difference in age was still observed after excluding 11 paediatric (18 years or below) cases ( 2 oligodendrogliomas, 1 anaplastic oligodendroglioma and 8 oligoastrocytomas) (46.2 years vs 41.4 years, $p=0.023$ ) (Supplementary Figure S1a). Prognostically, classic oligodendroglial histology was also associated with better prognosis across the $1 \mathrm{p} / 19 \mathrm{q}$ noncodeleted cohort $(p<0.000001)$ (Figure 2e). Correlating (a)

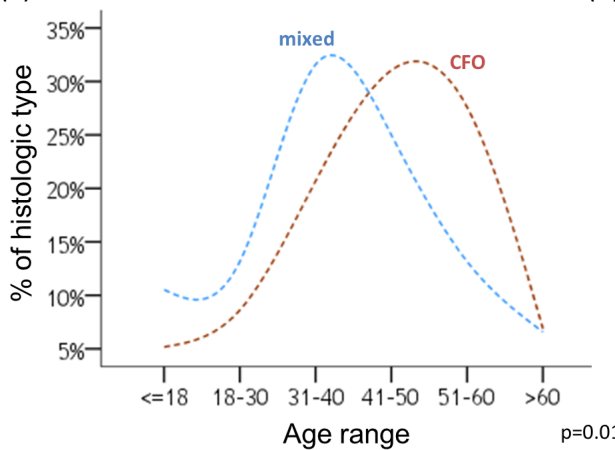

(c)

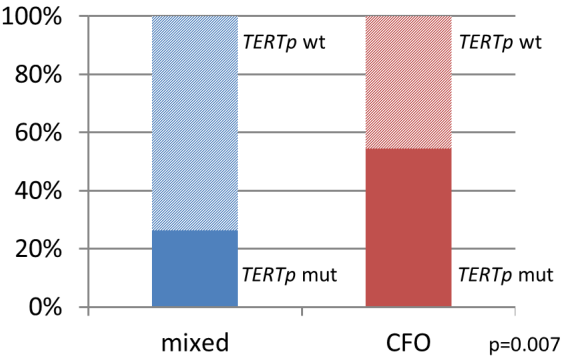

(b)

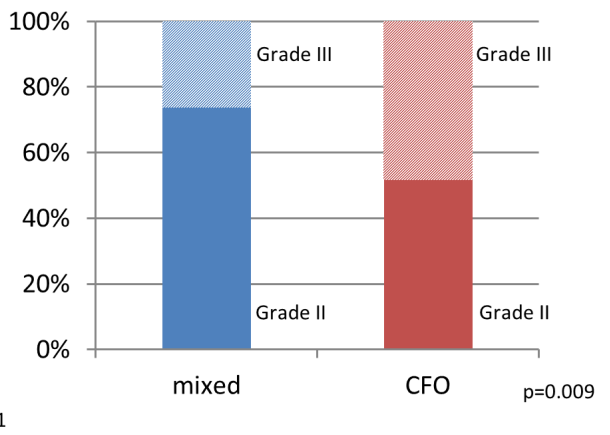

(d)

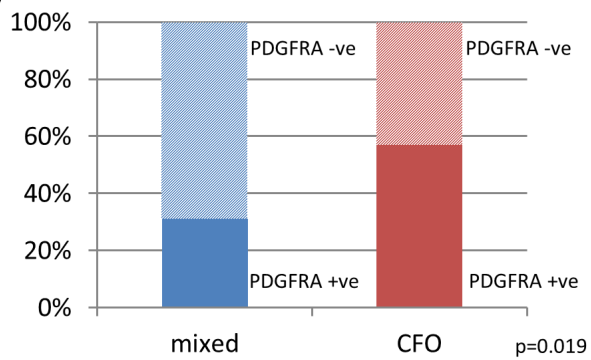

(e)

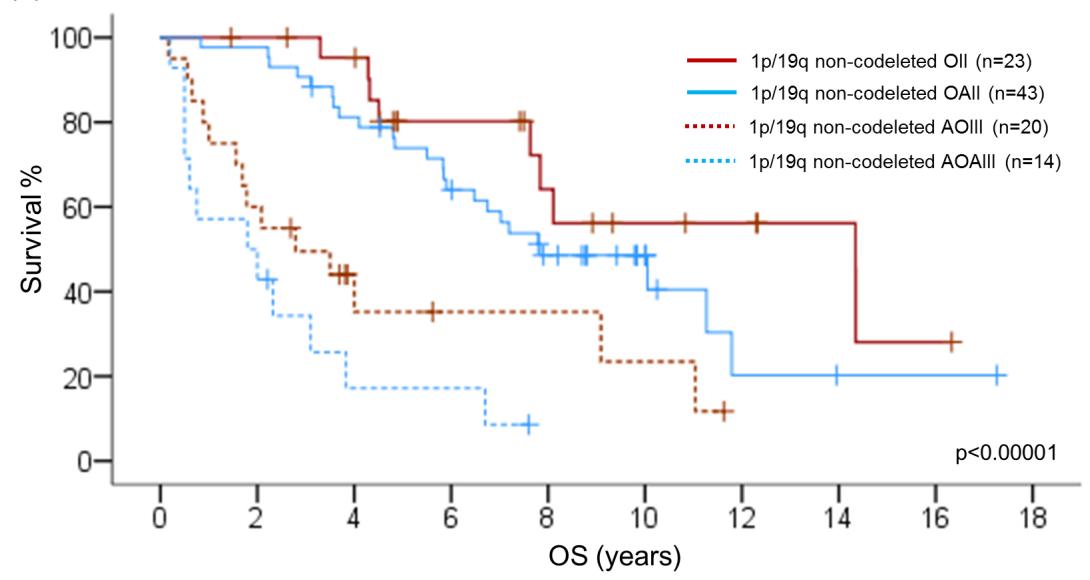

Figure 2: Correlations between clinicopathological factors and molecular variables among 1p/19q intact oligodendroglial tumors. Patients with classic oligodendroglial histology were significantly older than those with mixed oligoastrocytic histology $(p$ $=0.01)$ a. Grade III histology was more common in oligodendrogliomas $(48.3 \%)$ than oligoastrocytomas $(26.3 \%)$ among $1 \mathrm{p} / 19 \mathrm{q}$ noncodeleted tumors b. Classic oligodendroglial histology in a background of non-codeleted $1 \mathrm{p} / 19 \mathrm{q}$ was associated with $p$ mutation $(p=$ $0.007)$ c. and positive PDGFRA expression $(p=0.019)$ d. Kaplan-Meier curves for overall survival (OS) of tumor histology in $1 \mathrm{p} / 19 \mathrm{q}$ intact oligodendroglial tumors e. CFO, classic for oligodendroglial morphology; mixed, mixed oligoastrocytic histology; mut, mutant; wt, wild-type; -ve, negative; +ve, positive; OS, overall survival. 
Table 4: Review of various retrospective cohorts and important clinical trials

\begin{tabular}{|c|c|c|c|c|c|}
\hline Study & $\begin{array}{l}\text { No. of } \mathrm{O} \\
\text { examined }\end{array}$ & $\begin{array}{l}\text { No. of } \mathrm{AO} \\
\text { examined }\end{array}$ & $\begin{array}{c}\text { No. of non- } 1 \mathrm{p} / 19 \mathrm{q} \\
\text { codeleted O identified }\end{array}$ & $\begin{array}{c}\text { No. of non- } 1 \mathrm{p} / 19 \mathrm{q} \\
\text { codeleted AO identified }\end{array}$ & Method used \\
\hline Ducray F and Sanson M et al. 2008 [25] & 22 & 24 & $9(40.9 \%)$ & $12(50 \%)$ & array-CGH \\
\hline Durand KS and Labrousse FJ et al. 2010 [30] & 2 & 5 & 0 & 0 & $\mathrm{LOH}$ \\
\hline Labussiere M and Sanson M et al. 2010 [27] & 90 & 119 & $43(47.8 \%)$ & $55(46.2 \%)$ & array-CGH \\
\hline Buckley PG and Farrell MA et al. 2011 [33] & 15 & 12 & $3(20 \%)$ & $3(25 \%)$ & FISH and array-CGH \\
\hline Ducray F and Sanson M et al. 2011 [35] & 73 & 133 & $30(51 \%)$ & $42(45 \%)$ & array-CGH \\
\hline Eigenbrod S and Kretzschmar HA et al. 2011 [37] & 10 & 10 & $1(10 \%)$ & $4(40 \%)$ & $\mathrm{LOH}$ \\
\hline Goze C and Duffau H et al. 2012 [29] & 21 & - & $6(29 \%)$ & - & LOH \\
\hline Jiao $\mathrm{Y}$ and $\mathrm{Yan} \mathrm{H}$ et al. 2012 [36] & 21 & 29 & $8(38.1 \%)$ & $3(10.3 \%)$ & $\mathrm{LOH}$ \\
\hline Li S and Jiang T et al. 2012 [14] & - & 36 & - & $22(61.1 \%)$ & DHPLC \\
\hline Sahm F and Hartmann C et al. 2012 [34] & 9 & 9 & $2(22.2 \%)$ & $1(11.1 \%)$ & LOH and MLPA \\
\hline Arita $\mathrm{H}$ and Ichimura $\mathrm{K}$ et al. 2013 [10] & 34 & 31 & $7(23 \%)$ & $7(27 \%)$ & MLPA \\
\hline Cairncross G and Mehta M et al. 2013 [1] & - & 150 & - & $43(29 \%)$ & FISH \\
\hline Frenel JS and Campone M et al. 2013 [32] & 0 & 43 & 0 & $17(42.5 \%)$ & FISH \\
\hline Jiang H and Lin S et al. 2013 [28] & - & 24 & - & $7(29.2 \%)$ & FISH \\
\hline Mur P and Melendez B et al. 2013 [31] & 19 & 14 & \multicolumn{2}{|c|}{$14(42.4 \%)$} & FISH \\
\hline van den Bent MJ and Hoang-Xuan K et al.2013 [5] & - & $\begin{array}{c}316(\mathrm{AO} \text { and } \\
\mathrm{AOA})\end{array}$ & - & $\begin{array}{c}236(75 \%, \mathrm{AO} \text { and } \\
\mathrm{AOA})\end{array}$ & FISH \\
\hline Chan AK and Ng HK et al.2014 [15] & 19 & 11 & $7(36.8 \%)$ & $4(36.4 \%)$ & FISH \\
\hline Gillet E and Idbaih A et al. 2014 [23] & 32 & - & $16(50 \%)$ & - & $\mathrm{LOH}$ \\
\hline Sahm F and von Deimling A et al. 2014 [11] & \multicolumn{2}{|c|}{$43(\mathrm{OA})$} & \multicolumn{2}{|c|}{$11(25.6 \%, \mathrm{OA})$} & FISH \\
\hline Brat DJ and Zhang J et al. 2015 [51] & 65 & 44 & $27(41.5 \%)$ & $13(29.5 \%)$ & Genomic Analysis \\
\hline Chan $\mathrm{AK}$ and $\mathrm{Ng}$ HK et al.2015 [6] & 18 & 3 & $7(41.2 \%)$ & $1(33.3 \%)$ & FISH \\
\hline Gleize V and Sanson M et al. 2015 [24] & 60 & 43 & $4(6.7 \%)$ & $9(20.9 \%)$ & $\mathrm{LOH}$ \\
\hline Weller M and Reifenberger G et al. 2015 [26] & 3 & 3 & 0 & $1(33.3 \%)$ & array-CGH \\
\hline Dubbink HJ and van den Bent MJ et al. 2016 [22] & - & 93 & - & $40(47.1 \%)$ & LOH, FISH and NGS \\
\hline
\end{tabular}

O, oligodendroglioma; AO, anaplastic oligodendroglioma; OA, Oligoastrocytoma; FISH, fluorescence in situ hybridization; LOH, loss of heterozygosity; MLPA, multiplex ligation-dependent probe amplification; DHPLC, denaturing high-performance liquid chromatography; NGS, next-generation sequencing; array-CGH, array-based comparative genomic hybridization 
(a)

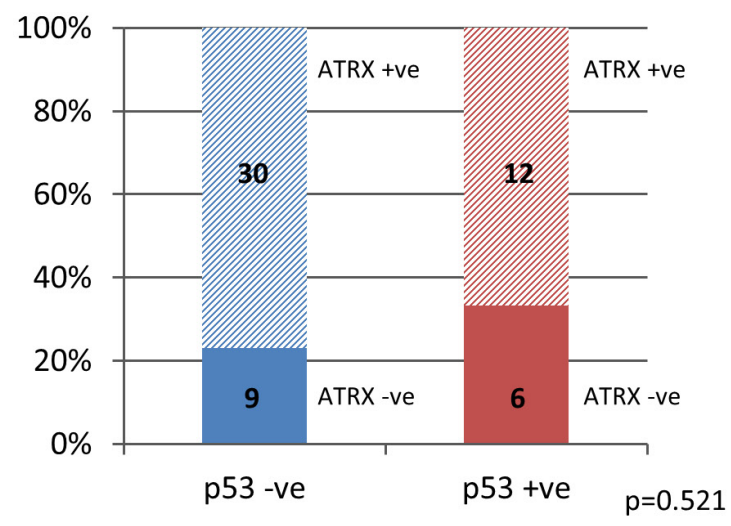

(b)

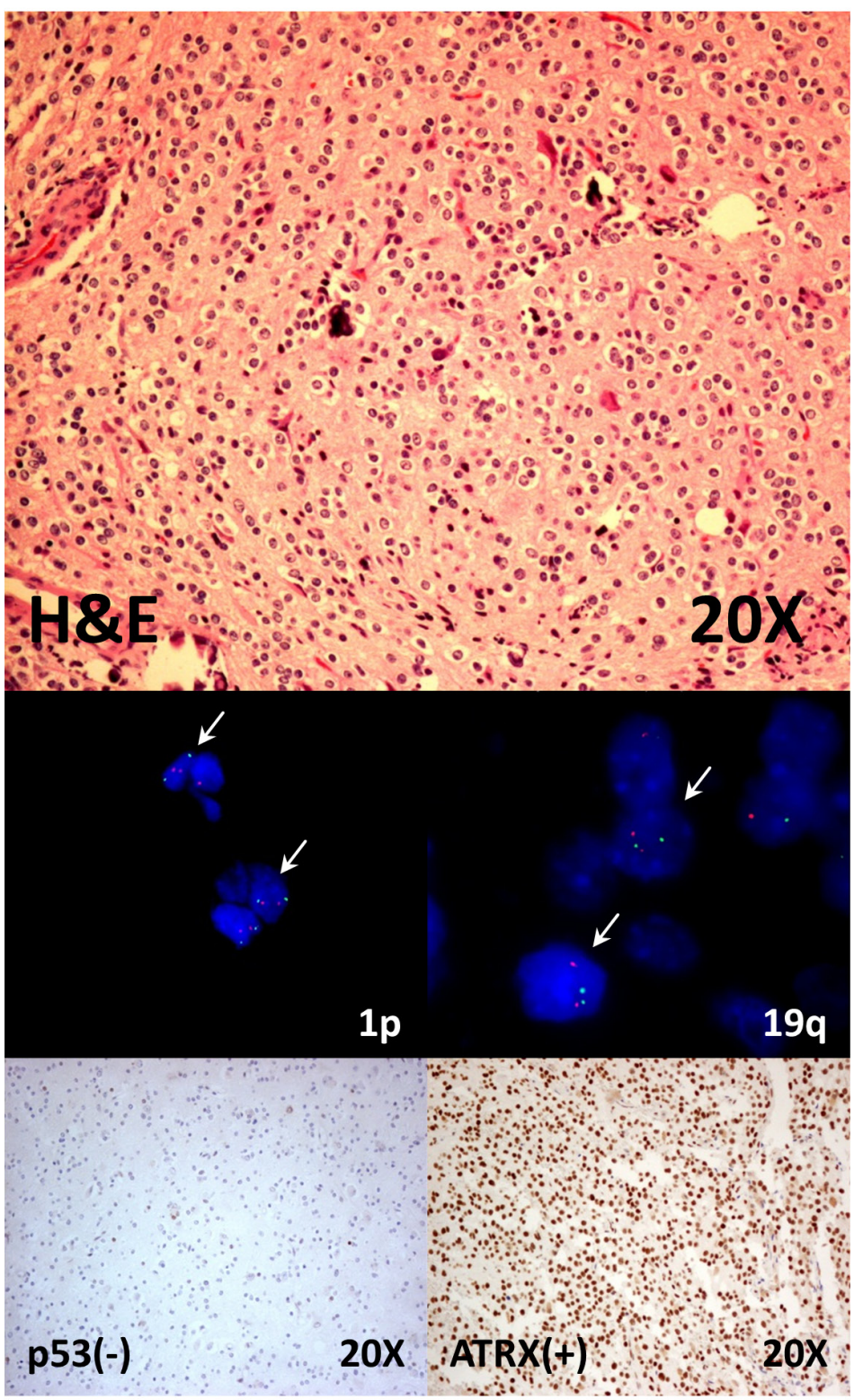

Figure 3: Co-evaluation of p53 and ATRX immunohistochemistry in 1p/19q non-codeleted oligodendroglial tumors. $52.6 \%(30 / 57)$ of $1 p / 19 q$ non-codeleted oligodendroglial tumors lacking p53 positivity and loss of ATRX expression a. Photos of 1p/19q intact oligodendroglioma with negative p53 expression and positive ATRX staining b. -ve, negative; +ve, positive. 
with histologic grade, $48.3 \%(28 / 58)$ of $1 \mathrm{p} / 19 \mathrm{q}$ noncodeleted oligodendrogliomas showed grade III histology, compared to $26.3 \%(20 / 76)$ in $1 p / 19 q$ non-codeleted oligoastrocytomas ( $p=0.009$ ) (Figure 2b). Molecularly, classic oligodendroglial histology in a background of non-codeleted $1 \mathrm{p} / 19 \mathrm{q}$ was also associated with TERTp mutation ( $p=0.007$ ) (Figure $2 \mathrm{c}$ ) and showed frequent $I D H$ mutation (67.4\%) (Supplementary Figure S1b). In a subset of the $1 \mathrm{p} / 19 \mathrm{q}$ non-codeleted tumors $(\mathrm{N}=80)$, PDGFRA immunohistochemical expression was also evaluated and classic oligodendroglial histology was associated with positive PDGFRA expression $(p=0.019)$ (Figure 2d).

\section{Infrequent astrocytic markers identified in $1 p / 19 q$ non-codeleted oligodendroglial tumors}

To further interrogate lineage of the oligodendrogliomas lacking $1 \mathrm{p} / 19 \mathrm{q}$ codeletion, $\mathrm{p} 53$ and ATRX immunohistochemical expression were also evaluated. p53 immunohistochemistry positivity was detectable in only $30 \%$ of $1 \mathrm{p} / 19 \mathrm{q}$ non-codeleted oligodendroglial tumors among 90 cases examined, including seven anaplastic oligodendrogliomas, 13 oligoastrocytomas and seven anaplastic oligoastrocytomas (Supplementary Figure S1c). Among 70 cases of 1p/19q non-codeleted gliomas examined for ATRX expression, internal positivity was detected in 61 cases and only $26.2 \%(16 / 61)$ of cases demonstrated ATRX loss. $83.3 \%$ $(15 / 18)$ of oligodendrogliomas and $69.8 \%$ (30/43) of (a)

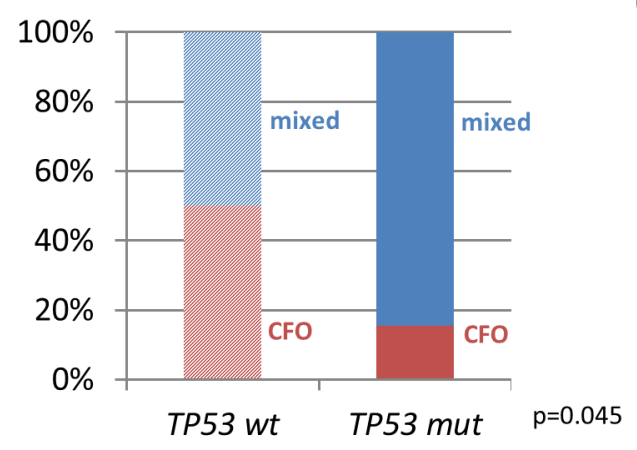

(c) (b)

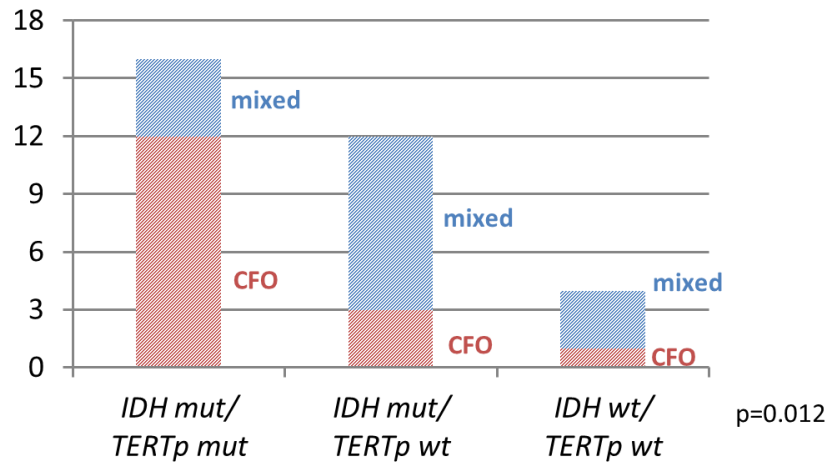

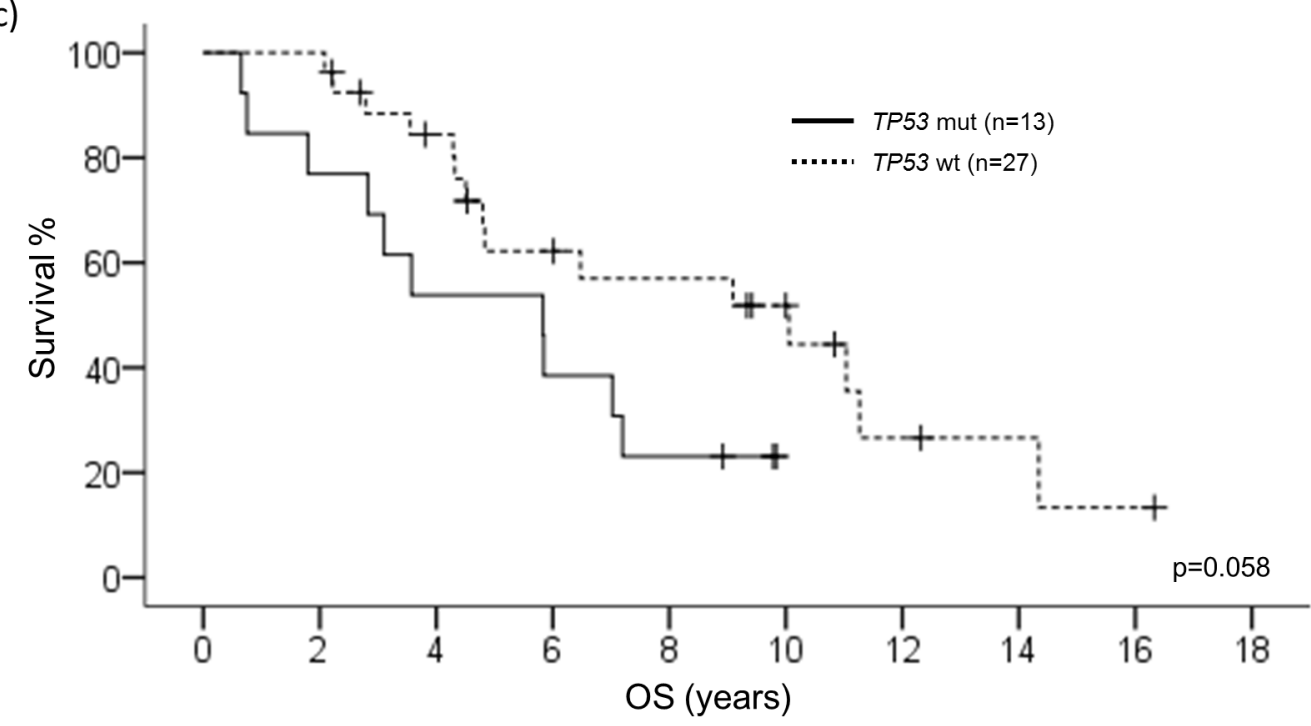

Figure 4: Correlations between TP53 mutational status and clinicopathological and molecular variables. Half of TP53 wild-type tumors showed classic oligodendroglial histology $(p=0.045)$ a. Mutations of IDH and TERTp co-occurred in $75 \%$ of oligodendrogliomas without $1 \mathrm{p} / 19 \mathrm{q}$ codeletion and TP53 mutation $(p=0.012)$ b. Patients with Wild-type TP53 tend to have better survival $(p=0.058)$ c. CFO, classic for oligodendroglial morphology; mixed, mixed oligoastrocytic histology; mut, mutant; wt, wild-type; OS, overall survival. 
oligoastrocytomas showed ATRX positivity even in a background of intact 1p/19q (Supplementary Figure S1d). Co-evaluation of p53 and ATRX immunohistochemistry identified $52.6 \%(30 / 57)$ of $1 \mathrm{p} / 19 \mathrm{q}$ non-codeleted oligodendroglial tumors lacking the important astrocytic markers (Figure 3).

\section{$1 p / 19 q$ non-codeleted oligodendroglial tumors with wild-type $T P 53$ are frequently IDH/TERTP mutated}

We additionally conducted mutational analysis of TP53 (exon 4 to 9) in 45 cases of oligodendroglial tumors lacking $1 \mathrm{p} / 19 \mathrm{q}$ codeletion. TP53 mutations detected were summarized in Supplementary Table S2. Wildtype TP53 was observed in $71.1 \%(32 / 45)$ of $1 \mathrm{p} / 19 \mathrm{q}$ non-codeleted oligodendroglial tumors and trended to better survival $(p=0.058)$ (Figure $4 c)$. Importantly, $50 \%$ (16/32) of TP53 wild-type tumors showed classic oligodendroglial histology $(p=0.045)$ (Figure 4a). Among this subset of $1 \mathrm{p} / 19 \mathrm{q}$ non-codeleted, TP53 wildtype oligodendroglial tumors, IDH and TERTp mutations were present in $87.5 \%(28 / 32)$ and $50 \%(16 / 32)$ of cases, respectively. The mutations co-occurred in $75 \%(12 / 16)$ of oligodendrogliomas without $1 \mathrm{p} / 19 \mathrm{q}$ codeletion and TP53 mutation $(p=0.012$ ) (Figure $4 \mathrm{~b})$.

\section{DISCUSSION}

In the present study, we examined a large cohort of oligodendroglial tumors $(\mathrm{N}=337)$ and identified $60.2 \%$ of cases harbored $1 \mathrm{p} / 19 \mathrm{q}$ codeletion. Since first reported by Reifenberger and colleagues in 1994 [16], combined chromosomal whole arm deletion in $1 p$ and $19 q$ has been referred as genetic hallmark of oligodendrogliomas [17]. Mediated by an unbalanced translocation between chromosome 1 and 19, with formation of derivative chromosomes der(1;19)(q10;p10) and der(1;19)(p10;q10)

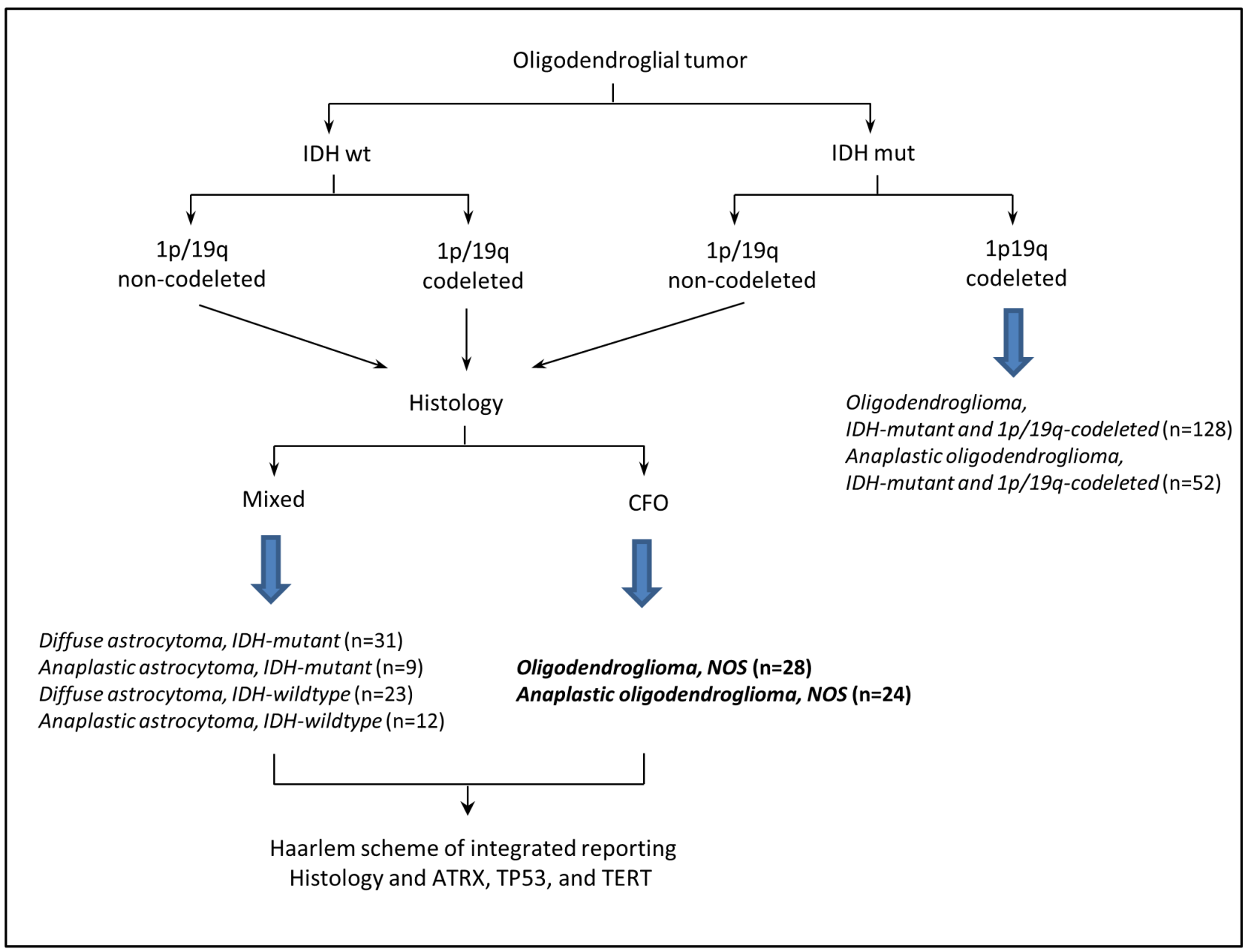

Figure 5: Overview of the sequential work-flow based on The 2016 WHO classification of CNS tumors and Haarlem scheme $[\mathbf{2 0}, \mathbf{5 6}]$. mixed, mixed oligoastrocytic histology; CFO, classic for oligodendroglial morphology. 
and the latter one being subsequently deleted during gliomagenesis $[13,18], 1 \mathrm{p} / 19 \mathrm{q}$ codeletion was one of the most representative and remarkable molecular markers in diffuse gliomas with diagnostic, prognostic and predictive utilities in clinical practice [7, 19]. The marker served as a stratifier in clinical trials and was shown to predict therapeutic response to PCV chemotherapy (procarbazine, lomustine and vincristine) and radiotherapy in oligodendroglial tumors $[1,5] .1 \mathrm{p} / 19 \mathrm{q}$ codeletion will be one of the molecular markers being incorporated into the integrated morphological and molecular diagnosis of CNS tumors as proposed by the International Society of Neuropathology-Haarlem Consensus Guidelines [20].

While classical oligodendrogliomas would be defined by $1 \mathrm{p} / 19 \mathrm{q}$ codeletion [7], there were clearly oligodendroglial tumors lacking the molecular hallmark in various retrospective cohorts and important clinical trials, some of which with histology having been vigorously interrogated by a central review panel of experienced neuropathologists $[1,5,6,10,11,14,15,21$ 37] (Table 4). In the EORTC 26951 study, $75 \%$ of 316 oligodendroglial tumors had non-codeleted $1 \mathrm{p} / 19 \mathrm{q}$ and 175 cases were oligodendroglioma [5]. In the RTOG 9402 trial, $29 \%$ of 150 oligodendroglial tumors had intact $1 p$ or 19q alleles [1], when the histology of the same cohort was subject to central panel review, 20\% (19/97) of the CFO (classic for oligodendroglial morphology) tumors had intact $1 \mathrm{p} / 19 \mathrm{q}$ [38]. So clearly, "oligodendroglial tumors" without $1 \mathrm{p} / 19 \mathrm{q}$ codeletion are a distinct, sizeable group which cannot be put aside. In our study, we identified $24 \%(30 / 125)$ of oligodendrogliomas and $38.9 \%(28 / 72)$ of anaplastic oligodendrogliomas had intact $1 \mathrm{p}$ or $19 \mathrm{q}$, yielding an overall frequency of $1 \mathrm{p} / 19 \mathrm{q}$ noncodeleted oligodendrogliomas of $29.4 \%$ (58/197). Our results corroborated the observations of the existence of $1 \mathrm{p} / 19 \mathrm{q}$ intact oligodendrogliomas from previous studies and suggested the need of additional biomarker(s) to characterize this subset of oligodendrogliomas.

Genomic landscape of grades II and III diffuse gliomas was comprehensively interrogated in the landmark study reported by the TCGA Research Network using multi-omic platforms [39]. The genomewide analyses identified concordant classification of three prognostically relevant molecular subgroups of lower grade gliomas based on unsupervised clustering of multi-omic data, which can be robustly identified by $I D H$ mutation and $1 \mathrm{p} / 19 \mathrm{q}$ codeletion. Importantly, $I D H$ mutated, $1 \mathrm{p} / 19 \mathrm{q}$ codeleted gliomas were characterized by mutations in CIC, FUBP1, NOTCH1, and TERT promoter, suggesting these mutations could serve as oligodendroglial lineage markers. IDH mutated gliomas lacking $1 \mathrm{p} / 19 \mathrm{q}$ codeletion showed high frequency of TP53 mutation (94\%) and ATRX inactivation (86\%), compatible with their role as astrocytic markers. These substantial genomic data provided the basis of our choice of astrocytic and oligodendroglial markers in our current study
(Supplementary Table S3). It was worthwhile to note that in the TCGA report, OncoSign analysis based on recurrent copy-number variations, mutations, and gene fusions, was performed and the group identified four dominant OncoSign classes, namely OSC 1 to OSC4, which were correlated with the $I D H-1 \mathrm{p} / 19 \mathrm{q}$ defined subgroups. $1 \mathrm{p} / 19 \mathrm{q}$ non-codeleted oligodendrogliomas were enriched in OSC 3 and were associated with $I D H$ mutation and TERTp mutation, validating the observations in our study. Another remarkable study from Weller et al. interrogated grades II and III diffuse gliomas using genome- and transcriptomewide profiling and reported molecular subgroups harboring distinct genomic aberrations and expression patterns which provided prognostically significant information on top of $I D H$ mutation and $1 \mathrm{p} / 19 \mathrm{q}$ codeletion [26]. Genomic profiling revealed five molecular subgroups with Group I tightly correlating with $I D H$ mutation and $1 \mathrm{p} / 19 \mathrm{q}$ codeletion and exhibiting the best clinical outcome, and Group V harboring glioblastoma-like copy number changes including 7q gain and 10q loss, and showing the poorest survival. Importantly, the genomic profiling provided clinically relevant information with biological implication for prognostication of diffuse gliomas beyond histologic classification and grading.

$1 \mathrm{p} / 19 \mathrm{q}$ non-codeleted oligodendrogliomas in our study were associated with TERTp mutation $(p=0.007)$ and demonstrated frequent $I D H$ mutation (67.4\%). Comutations of $I D H$ and TERTp occurred in $75 \%$ of $1 \mathrm{p} / 19 \mathrm{q}$ intact, TP53 wild-type oligodendrogliomas in our cohort. Notably, $I D H$ mutation was also frequently detected in the $1 \mathrm{p} / 19 \mathrm{q}$ intact oligodendroglial tumors and conferred chemo-radiation sensitivity in the absence of $1 p / 19 q$ codeletion as shown by Cairncross and colleagues [21]. In terms of classification and diagnostic utility, presence of IDH mutation, even without $1 \mathrm{p} / 19 \mathrm{q}$ codeletion, has been suggested to indicate the diagnosis of oligodendrogliomas over other tumors with similar histo-morphological features [40]. Multiple studies have shown the association between TERTp mutation and $1 \mathrm{p} / 19 \mathrm{q}$ codeletion as well as classic oligodendroglial morphology $[6,9,10,41,42]$. Our current study validated previous observations and additionally demonstrated the association between TERTp mutation and classic oligodendroglial morphology in a molecular background of intact 1p/19q. Notably, in the study by Killela and colleagues examining more than 470 diffuse gliomas, co-mutations of IDH and TERTp were identified in $79.3 \%(69 / 87)$ of oligodendrogliomas while $1 \mathrm{p} / 19 \mathrm{q}$ codeletion was only observed in $54 \%(47 / 87)$ of the cases [41]. Our study and previous observations suggested the potential of $I D H$ mutation plus TERTp mutation in assisting the diagnosis of oligodendroglioma for a tumor with clear cell morphology but lacking $1 \mathrm{p} / 19 \mathrm{q}$ codeletion.

It was crucial to avoid misclassification of true $1 \mathrm{p} / 19 \mathrm{q}$ codeleted oligodendrogliomas as non-deleted tumors (ie false negativity) in our study. We employed 
FISH and used commercial probe targeting the "minimally deleted regions" [43-45] in order to maximize the sensitivity in detecting $1 \mathrm{p} / 19 \mathrm{q}$ codeletion [2]. The technique had been well standardized and adopted in various studies [28, 31-33, 38] and could be applied robustly on formalin-fixed paraffin-embedded tissues in routine diagnostic neuropathology practice. Importantly, FISH probes targeting at the same loci were also adopted by the EORTC and RTOG clinical trials $[1,5]$. Since $1 \mathrm{p} / 19 \mathrm{q}$ loss classically involved deletion of the entire $1 \mathrm{p}$ and $19 q$ arms, tumors with retained minimally deleted regions in our study were extremely unlikely to be false negative cases.

We further examined astrocytic markers, p53 expression and ATRX loss, in the 1p/19q non-codeleted oligodendroglial tumors. Co-evaluation of the two astrocytic immuno-markers revealed more than 50\% of the $1 \mathrm{p} / 19 \mathrm{q}$ non-codeleted oligodendroglial tumors did not show p53 positivity and ATRX loss, i.e. they were not molecularly astrocytic. Among 38 cases of mixed oligoastrocytomas with analyzable data of ATRX expression and TERTp mutation, the two biomarkers showed mutual exclusivity in all but one case [Supplementary Figure S1e]. TERTp and ATRX mutations represented independent genetic mechanisms in maintaining telomere lengths in tumorigenesis of diffuse gliomas [42]. In the study by Sahm and colleagues investigating 43 mixed oligoastrocytomas, 1p/19q codeletion and ATRX loss were mutually exclusive in all but one case, suggesting parting with the diagnosis of oligoastrocytoma. According to these authors, all noncodeleted oligodendroglial tumors are in fact astrocytic [11]. With the morphological and molecular evidence of several cases of "true" oligoastrocytoma being reported [46-48], complete farewell to oligoastrocytoma can be argued. Notably, in our series, we also did not find any true cases of "oligoastrocytoma".

Clinical trials by Cairncross et al. and van den Bent et al. have set the standard therapeutic protocol for patients with $1 \mathrm{p} / 19 \mathrm{q}$ codeleted anaplastic oligodendroglial tumors $[1,5]$. The former research group has additionally demonstrated that the survival benefit of PCV (procarbazine, lomustine, and vincristine) in $1 \mathrm{p} / 19 \mathrm{q}$ non-codeleted anaplastic oligodendroglial tumors was associated with $I D H$ mutation [21]. Clinical benefits of radiation plus PCV have been extended to treatment of low grade diffuse gliomas [49]. The chemoradiotherapy was associated with prolonged overall survival and progression-free survival in subsets of oligodendroglioma, oligoastrocytoma, and $I D H$ mutated low grade gliomas. Our group has previously reported the potential clinical value of TERTp mutation in predicting differential responses to genotoxic therapies in grades II and III diffuse gliomas, on top on $I D H$ status [50]. Our current study identified a major portion of oligodendrogliomas lacking $1 \mathrm{p} / 19 \mathrm{q}$ codeletion was characterized by $I D H$ and
TERTp co-mutation, with a background of ATRX nuclear positivity wild-type TP53 (Figure 5), indicating that these patients could potentially benefit from chemoradiotherapy.

In summary, this study examined a large cohort of oligodendroglial tumors and demonstrated that astrocytic tumors could not account for all $1 \mathrm{p} / 19 \mathrm{q}$ non-codeleted oligodendroglial tumors and oligodendroglioma lacking $1 \mathrm{p} / 19 \mathrm{q}$ codeletion may form a distinct subgroup of diffuse glioma. Co-evaluation of IDH and TERTp mutation had diagnostic value for oligodendroglioma and could serve as an adjunct in oligodendroglial tumors after evaluation of the $1 \mathrm{p} / 19 \mathrm{q}$ status.

\section{MATERIALS AND METHODS}

\section{Patients and tissue samples}

Oligodendroglial tumors diagnosed from our service archives at the Prince of Wales Hospital (The Chinese University of Hong Kong) and Huashan Hospital (Fudan University, Shanghai) were included in the present study. Totally 337 oligodendroglial tumors were included in our study and 71 of them were from Hong Kong and 266 from Shanghai. Only cases which were reviewed by two neuropathologists (HK N and $\mathrm{H} \mathrm{C}$ ) as oligodendroglial were included based on The 2007 WHO classification of tumors of the central nervous system [51]. The present study used only formalin-fixed, paraffin-embedded material. Clinical and survival data of the patients were retrieved from the respective institutional medical record systems. This study was approved by the Ethics Committee of Shanghai Huashan Hospital and the New Territories East Cluster-Chinese University of Hong Kong Ethics Committee. The cohort in this study partially overlapped with previous studies $[6,15,52]$.

\section{Fluorescence In Situ hybridization for chromosome 1p and 19q}

Fluorescent in situ hybridization (FISH) was performed on formalin-fixed, paraffin-embedded tumor tissue to detect deletion of chromosome $1 p$ and $19 q$ [15]. 4- $\mu \mathrm{m}$-thick sections were deparaffinized, treated with sodium thiocyanate and followed by digestion with pepsin solution at $37^{\circ} \mathrm{C}$. Dual-color-probe hybridization was then performed using Vysis 1p36/1q25 and 19q13/19p13 FISH Probe Kit (Abbott Molecular) and the spectrum-green-probe was labeled on chromosome $1 \mathrm{q}$ and $19 \mathrm{p}$, respectively. Both probes and target tumor DNA were denatured in an $80^{\circ} \mathrm{C}$ oven for 30 minutes and followed by an overnight incubation at $37^{\circ} \mathrm{C}$. Nuclei were counterstained with Vectashield mounting medium containing 4', 6-diamidino-2- phenylindole (Vector Laboratories, Burlingame, CA, USA) and the number 
of FISH signals was assessed under a Zeiss Axioplan fluorescence microscope (Carl Zeiss Microscopy LLC, NY, USA) equipped with a triple-pass filter (DAPI/ Green/Orange). Hybridizing signals of at least 100 nonoverlapping nuclei were enumerated and a sample will be considered as 1 p or $19 q$ deleted when more than $25 \%$ of counted nuclei presented one target (orange) signal and two reference (green) signals [2].

\section{Mutation analysis of $I D H 1 / 2, T E R T$ promoter and TP53}

Mutation status of $I D H 1 / 2, T E R T$ promoter and TP53 were studied with direct sequencing $[6,52,53]$. Tissues from representative areas with tumor content $>70 \%$ were collected from 5 to 7 dewaxed formalinfixed, paraffin-embedded sections and re-suspended in $10 \mathrm{mM}$ Tris- $\mathrm{HCl}$ buffer ( $\mathrm{pH} 8.5$ ) which also contained proteinase $\mathrm{K}$ with a final concentration of $2 \mathrm{mg} / \mathrm{ml}$. After that, the mixture was incubated at $55^{\circ} \mathrm{C}$ for $2-18 \mathrm{~h}$ and then at $98^{\circ} \mathrm{C}$ for $10 \mathrm{~min}$. After the above incubation, the buffer comprising the cell lysate was used for polymerase chain reaction (PCR) analysis of IDH1, IDH2, TP53 and TERTp. We performed direct sequencing for $I D H 1$, IDH2, TERT promoter region and exon 4-9 of TP53 as per previous protocols $[6,15,52-54]$. All mutational status was validated by sequencing of a newly amplified DNA fragment. Sequences of primers used for PCR analysis of IDH1/2, TERT promoter and TP53 were listed in Supplementary Table S1. For sequencing of $I D H 1 / 2$ and TP53, target DNA fragments were amplified in a total $10 \mu \mathrm{l}$ reaction volume which containing $1 \mu \mathrm{l}$ of cell lysate, $1 \mu \mathrm{l}$ of $\mathrm{MgCl} 2(25 \mathrm{mM}), 1 \mu \mathrm{l}$ of $10 *$ PCR buffer II, $0.2 \mu \mathrm{l}$ of each deoxyribonucleoside triphosphate $(10 \mathrm{mM}), 0.3 \mu \mathrm{l}$ of each forward and reverse primers of target DNA fragment (10nmol), $0.075 \mu \mathrm{l}$ of AmpliTaq Gold DNA polymerase (Life Technologies Corporation, Hong Kong, China). PCR for TERT promoter region was performed in $10 \mu$ reaction mixture containing $1 \mu \mathrm{l}$ of cell lysate, $0.3 \mu \mathrm{l}$ of each forward and reverse primers of target DNA fragment (10nmol), and $5 \mu \mathrm{l}$ of KAPA HiFi HotStart ReadyMix DNA Polymerase (Kapa Biosystems Wilmington, DE, USA). PCR reaction started with a denature procedure of $95^{\circ} \mathrm{C}$ for $10 \mathrm{~min}$, then followed by 45 cycles of $95^{\circ} \mathrm{C}$ for $20 \mathrm{sec}$, annealing temperature (Supplementary Table 1) for $20 \mathrm{sec}$ and $72^{\circ} \mathrm{C}$ for $30 \mathrm{sec}$, and a final extension step of $72^{\circ} \mathrm{C}$ for $3 \mathrm{~min}$. Products were then treated with Exonuclease I (TakaRa Biotechnology Limited, Dalian, China) of $2 \mu \mathrm{l}(0.25 \mathrm{U} /$ $\mu \mathrm{l})$ per $5 \mu \mathrm{l} \mathrm{PCR}$ product at $37^{\circ} \mathrm{C}$ for $15 \mathrm{~min}$ followed by $80^{\circ} \mathrm{C}$ for $15 \mathrm{~min}$. Sequencing of target DNA fragment was performed using BigDye Terminator Cycle Sequencing kit v.1.1 (Life Technologies). The Genetic Analyzer 3130xl was used for the following sequencing and the results were analyzed by Sequencing Analysis Software. Hotspot mutations of IDH1/2 and TERTp, all missense mutations of TP53 could be detected. All detected missense mutations of TP53 were listed in Supplementary Table S2.

\section{Immunohistochemistry of ATRX, p53 and PDGFRA}

Immunohistochemistry was performed for detecting the expression of p53, PDGFRA, and ATRX. $4 \mu \mathrm{m}$ thick formalin-fixed, paraffin-embedded (FFPE) sections of each sample were de-waxed by xylene and rehydrated in graded alcohols. Sections were then treated with citrate buffer $(\mathrm{pH}$ 6.0 ) by heating for antigen retrieval. After antigen retrieval, they were subjected to immuno-staining by BenchMark XT automated tissue staining systems (Ventana Medical Systems, Tucson, AZ, USA) using validated protocols for detecting the expression of p53 and ATRX. Sections were incubated with antibodies of anti-p53 (Dako DO-7, 1:100) and anti-ATRX (SIGMA CAT: HPA001906, 1:400) at $37^{\circ} \mathrm{C}$ for $32 \mathrm{~min}$ and followed by an incubation with UltraView HRP-conjugated multimer antibody reagent (Ventana Medical Systems). Subsequent antigen detection was performed using UltraView diamino benzidine chromogen step (Ventana Medical Systems). Expression of PDGFRA was detected using the automated Bond-max system (Leica Bond-Max) with anti-PDGFRA antibody (Santa Cruz, C-20, 1:200) and subsequent antigen detection was performed using Ultra View diamino benzidine chromogen step (Bond-Max). At last, slides were counterstained with Mayer's hematoxylin. A tumor was scored p53 positive if $>10 \%$ of tumor cells showed strong nuclear staining [53]. Samples with more than $10 \%$ of tumor cells showing positive nuclear staining of ATRX were scored as positive. Endothelial cells, cortical neurons and infiltrating inflammatory cells were generally positive and served as internal positive controls [12]. Cytoplasmic and membrane staining were considered for evaluation of PDGFRA expression. Both the distribution and intensity of staining were semi-quantitatively scored as previously reported [55].

\section{Statistical analysis}

Statistical analysis was performed using IBM SPSS Statistics Version 20 (IBM Corporation, NY, USA). Univariate analysis was conducted using Chisquare or Fisher's test to compare categorical variables. Independent-Samples T Test was used to compare mean age between 2 populations. Kaplan-Meier estimator and log rank test were performed for univariate survival analysis. Whereas a Cox proportional hazards model was employed for multivariate survival analysis. Statistical significance was considered when $p<0.05$ (two-side). 


\section{ACKNOWLEDGMENTS}

This study was supported by Health and Medical Research Fund of Hong Kong (grant no. 02133146), 973 Program (grant no: 2015CB755500), and Shanghai Sailing Program (grant no:16YF1415200).

\section{CONFLICTS OF INTEREST}

The authors declare no conflict of interest.

\section{REFERENCES}

1. Cairncross G, Wang M, Shaw E, Jenkins R, Brachman D, Buckner J, Fink K, Souhami L, Laperriere N, Curran W and Mehta M. Phase III trial of chemoradiotherapy for anaplastic oligodendroglioma: long-term results of RTOG 9402. Journal of clinical oncology. 2013; 31(3):337-343.

2. Horbinski C, Miller CR and Perry A. Gone FISHing: clinical lessons learned in brain tumor molecular diagnostics over the last decade. Brain pathology. 2011; 21(1):57-73.

3. Bourne TD and Schiff D. Update on molecular findings, management and outcome in low-grade gliomas. Nature reviews Neurology. 2010; 6(12):695-701.

4. Appin. CL and Brat DJ. Molecular Genetics of Gliomas. The Cancer Journal. 2014; 20(NO.1):66-72.

5. van den Bent MJ, Brandes AA, Taphoorn MJ, Kros JM, Kouwenhoven MC, Delattre JY, Bernsen HJ, Frenay M, Tijssen CC, Grisold W, Sipos L, Enting RH, French PJ, Dinjens WN, Vecht CJ, Allgeier A, et al. Adjuvant procarbazine, lomustine, and vincristine chemotherapy in newly diagnosed anaplastic oligodendroglioma: longterm follow-up of EORTC brain tumor group study 26951. Journal of clinical oncology. 2013; 31(3):344-350.

6. Chan AK, Yao Y, Zhang Z, Chung NY, Liu JS, Li KK, Shi Z, Chan DT, Poon WS, Zhou L and Ng HK. TERT promoter mutations contribute to subset prognostication of lower-grade gliomas. Modern pathology. Inc. 2015; 28(2):177-186.

7. Wesseling $P$, van den Bent $M$ and Perry A. Oligodendroglioma: pathology, molecular mechanisms and markers. Acta neuropathologica. 2015; 129(6):809-827.

8. Majumdar K, Radotra BD, Vasishta RK and Pathak A. Platelet-derived growth factor expression correlates with tumor grade and proliferative activity in human oligodendrogliomas. Surgical neurology. 2009; 72(1):5460.

9. Koelsche C, Sahm F, Capper D, Reuss D, Sturm D, Jones DT, Kool M, Northcott PA, Wiestler B, Bohmer K, Meyer J, Mawrin C, Hartmann C, Mittelbronn M, Platten M, Brokinkel B, et al. Distribution of TERT promoter mutations in pediatric and adult tumors of the nervous system. Acta neuropathologica. 2013; 126(6):907-915.

10. Arita H, Narita Y, Fukushima S, Tateishi K, Matsushita Y,
Yoshida A, Miyakita Y, Ohno M, Collins VP, Kawahara $\mathrm{N}$, Shibui $\mathrm{S}$ and Ichimura K. Upregulating mutations in the TERT promoter commonly occur in adult malignant gliomas and are strongly associated with total $1 \mathrm{p} 19 \mathrm{q}$ loss. Acta neuropathologica. 2013; 126(2):267-276.

11. Sahm F, Reuss D, Koelsche C, Capper D, Schittenhelm J, Heim S, Jones DT, Pfister SM, Herold-Mende C, Wick W, Mueller W, Hartmann C, Paulus W and von Deimling A. Farewell to oligoastrocytoma: in situ molecular genetics favor classification as either oligodendroglioma or astrocytoma. Acta neuropathologica. 2014; 128(4):551-559.

12. Wiestler B, Capper D, Holland-Letz T, Korshunov A, von Deimling A, Pfister SM, Platten M, Weller M and Wick W. ATRX loss refines the classification of anaplastic gliomas and identifies a subgroup of IDH mutant astrocytic tumors with better prognosis. Acta neuropathologica. 2013; 126(3):443-451.

13. Jenkins RB, Blair H, Ballman KV, Giannini C, Arusell RM, Law M, Flynn H, Passe S, Felten S, Brown PD, Shaw EG and Buckner JC. A t $(1 ; 19)(\mathrm{q} 10 ; \mathrm{p} 10)$ mediates the combined deletions of $1 p$ and $19 q$ and predicts a better prognosis of patients with oligodendroglioma. Cancer research. 2006; 66(20):9852-9861.

14. Li S, Yan C, Huang L, Qiu X, Wang $Z$ and Jiang T. Molecular prognostic factors of anaplastic oligodendroglial tumors and its relationship: a single institutional review of 77 patients from China. Neuro-oncology. 2012; 14(1):109116.

15. Chan AK, Pang JC, Chung NY, Li KK, Poon WS, Chan DT, Shi Z, Chen L, Zhou L and Ng HK. Loss of CIC and FUBP1 expressions are potential markers of shorter time to recurrence in oligodendroglial tumors. Modern pathology. 2014; 27(3):332-342.

16. Reifenberger J, Reifenberger G, Liu L, James CD, Wechsler W and Collins VP. Molecular Genetic Analysis of Oligodendroglial Tumors Shows Preferential Allelic Deletions on 19q and 1p. American Journal of Pathology. 1994; 145(No. 5):1175-1190.

17. Cairncross $G$ and Jenkins R. Gliomas With $1 \mathrm{p} / 19 \mathrm{q}$ Codeletion: a.k.a. Oligodendroglioma. The Cancer Journal. 2008; 14(6):352-357.

18. Griffin CA, Burger P, Morsberger L, Yonescu R, Swierczynski S, Weingart JD and Murphy KM. Identification of $\operatorname{der}(1 ; 19)(\mathrm{q} 10 ; \mathrm{p} 10)$ in Five Oligodendrogliomas Suggests Mechanism of Concurrent 1p and $19 q$ Loss. Journal of neuropathology and experimental neurology. 2006; 65(No. 10):988-994.

19. Brandner $\mathrm{S}$ and von Deimling A. Diagnostic, prognostic and predictive relevance of molecular markers in gliomas. Neuropathology and applied neurobiology. 2015; 41(6):694-720.

20. Louis DN, Perry A, Burger P, Ellison DW, Reifenberger G, von Deimling A, Aldape K, Brat D, Collins VP, Eberhart C, Figarella-Branger D, Fuller GN, Giangaspero F, Giannini 
C, Hawkins C, Kleihues P, et al. International Society Of Neuropathology-Haarlem consensus guidelines for nervous system tumor classification and grading. Brain pathology. 2014; 24(5):429-435.

21. Cairncross JG, Wang M, Jenkins RB, Shaw EG, Giannini C, Brachman DG, Buckner JC, Fink KL, Souhami L, Laperriere NJ, Huse JT, Mehta MP and Curran WJ, Jr. Benefit from procarbazine, lomustine, and vincristine in oligodendroglial tumors is associated with mutation of IDH. Journal of clinical oncology. 2014; 32(8):783-790.

22. Dubbink HJ, Atmodimedjo PN, Kros JM, French PJ, Sanson M, Idbaih A, Wesseling P, Enting R, Spliet W, Tijssen C, Dinjens WN, Gorlia T and van den Bent MJ. Molecular classification of anaplastic oligodendroglioma using next-generation sequencing: a report of the prospective randomized EORTC Brain Tumor Group 26951 phase III trial. Neuro-oncology. 2016; 18(3):388-400.

23. Gillet E, Alentorn A, Doukoure B, Mundwiller E, van Thuijl HF, Reijneveld JC, Medina JA, Liou A, Marie Y, Mokhtari K, Hoang-Xuan K, Sanson M, Delattre JY and Idbaih A. TP53 and p53 statuses and their clinical impact in diffuse low grade gliomas. Journal of neuro-oncology. 2014; 118(1):131-139.

24. Gleize V, Alentorn A, Connen de Kerillis L, Labussiere M, Nadaradjane AA, Mundwiller E, Ottolenghi C, Mangesius S, Rahimian A, Ducray F, network P, Mokhtari K, Villa $\mathrm{C}$ and Sanson M. CIC inactivating mutations identify aggressive subset of $1 \mathrm{p} 19 \mathrm{q}$ codeleted gliomas. Annals of neurology. 2015; 78(3):355-374.

25. Ducray F, Idbaih A, de Reynies A, Bieche I, Thillet J, Mokhtari K, Lair S, Marie Y, Paris S, Vidaud M, HoangXuan K, Delattre O, Delattre JY and Sanson M. Anaplastic oligodendrogliomas with 1p19q codeletion have a proneural gene expression profile. Molecular cancer. 2008; 7:41.

26. Weller M, Weber RG, Willscher E, Riehmer V, Hentschel B, Kreuz M, Felsberg J, Beyer U, Loffler-Wirth H, Kaulich K, Steinbach JP, Hartmann C, Gramatzki D, Schramm J, Westphal M, Schackert G, et al. Molecular classification of diffuse cerebral WHO grade II/III gliomas using genome- and transcriptome-wide profiling improves stratification of prognostically distinct patient groups. Acta neuropathologica. 2015; 129(5):679-693.

27. Labussiere M, Idbaih A, Wang XW, Marie Y, Boisselier B, Falet C, Paris S, Laffaire J, Carpentier C, Criniere E, Ducray F, Hallani SE, Mokhtari K, Hoang-Xuan K, Delattre JY and Sanson M. All the 1p19q codeleted gliomas are mutated on IDH1 or IDH2. Neurology. 2010; 74:18861890.

28. Jiang H, Ren X, Cui X, Wang J, Jia W, Zhou Z and Lin S. $1 \mathrm{p} / 19 \mathrm{q}$ codeletion and IDH1/2 mutation identified a subtype of anaplastic oligoastrocytomas with prognosis as favorable as anaplastic oligodendrogliomas. Neuro-oncology. 2013; 15(6):775-782.

29. Goze C, Bezzina C, Goze E, Rigau V, Maudelonde T, Bauchet L and Duffau H. 1P19Q loss but not IDH1 mutations influences WHO grade II gliomas spontaneous growth. Journal of neuro-oncology. 2012; 108(1):69-75.

30. Durand KS, Guillaudeau A, Weinbreck N, DeArmas R, Robert S, Chaunavel A, Pommepuy I, Bourthoumieu S, Caire F, Sturtz FG and Labrousse FJ. 1p19q LOH patterns and expression of p53 and Olig2 in gliomas: relation with histological types and prognosis. Modern pathology. 2010; 23(4):619-628.

31. Mur P, Mollejo M, Ruano Y, de Lope AR, Fiano C, Garcia JF, Castresana JS, Hernandez-Lain A, Rey JA and Melendez B. Codeletion of $1 p$ and $19 q$ determines distinct gene methylation and expression profiles in IDH-mutated oligodendroglial tumors. Acta neuropathologica. 2013; 126(2):277-289.

32. Frenel JS, Leux C, Loussouarn D, Le Loupp AG, Leclair F, Aumont M, Mervoyer A, Martin S, Denis MG and Campone M. Combining two biomarkers, IDH1/2 mutations and $1 \mathrm{p} / 19 \mathrm{q}$ codeletion, to stratify anaplastic oligodendroglioma in three groups: a single-center experience. Journal of neuro-oncology. 2013; 114(1):85-91.

33. Buckley PG, Alcock L, Heffernan J, Woods J, Brett F, Stallings RL and Farrell MA. Loss of Chromosome $1 \mathrm{p} / 19 \mathrm{q}$ in Oligodendroglial Tumors: Refinement of Chromosomal Critical Regions and Evaluation of Internexin Immunostaining as a Surrogate Marker. Journal of neuropathology and experimental neurology. 2011; 70(No. 3):177-182.

34. Sahm F, Koelsche C, Meyer J, Pusch S, Lindenberg $\mathrm{K}$, Mueller W, Herold-Mende C, von Deimling A and Hartmann C. CIC and FUBP1 mutations in oligodendrogliomas, oligoastrocytomas and astrocytomas. Acta neuropathologica. 2012; 123(6):853-860.

35. Ducray F, Mokhtari K, Criniere E, Idbaih A, Marie Y, Dehais C, Paris S, Carpentier C, Dieme MJ, Adam C, Hoang-Xuan K, Duyckaerts C, Delattre JY and Sanson M. Diagnostic and prognostic value of alpha internexin expression in a series of 409 gliomas. European journal of cancer. 2011; 47(5):802-808.

36. Jiao Y, Killela PJ, Reitman ZJ, Rasheed BA, Heaphy CM, de Wilde RF, Rodriguez FJ, Rosemberg S, Oba-Shinjo SM, Nagahashi Marie SK, Bettegowda C, Agrawal N, Lipp E, Pirozzi CJ, Lopez GY, He Y, et al. Frequent ATRX, CIC, and FUBP1 mutations refine the classification of malignant gliomas. Oncotarget. 2012; 3:709-722. doi: 10.18632/ oncotarget.588.

37. Eigenbrod S, Roeber S, Thon N, Giese A, Krieger A, Grasbon-Frodl E, Egensperger R, Tonn JC, Kreth F-W and Kretzschmar HA. $\alpha$-Internexin in the Diagnosis of Oligodendroglial Tumors and Association With 1p/19q Status. Journal of neuropathology and experimental neurology. 2011; 70(11):970-978.

38. Giannini C, Burger PC, Berkey BA, Cairncross JG, Jenkins RB, Mehta M, Curran WJ and Aldape K. Anaplastic oligodendroglial tumors: refining the correlation among histopathology, 1p 19q deletion and clinical outcome in 
Intergroup Radiation Therapy Oncology Group Trial 9402. Brain pathology. 2008; 18(3):360-369.

39. Cancer Genome Atlas Research N, Brat DJ, Verhaak RG, Aldape KD, Yung WK, Salama SR, Cooper LA, Rheinbay E, Miller CR, Vitucci M, Morozova O, Robertson AG, Noushmehr H, Laird PW, Cherniack AD, Akbani R, et al. Comprehensive, Integrative Genomic Analysis of Diffuse Lower-Grade Gliomas. The New England journal of medicine. 2015; 372(26):2481-2498.

40. Tanboon J, Williams EA and Louis DN. The Diagnostic Use of Immunohistochemical Surrogates for Signature Molecular Genetic Alterations in Gliomas. Journal of neuropathology and experimental neurology. 2015.

41. Killela PJ, Pirozzi CJ, Healy P, Reitman ZJ, Lipp E, Rasheed BA, Yang R, Diplas BH, Wang Z, Greer PK, Zhu H, Wang CY, Carpenter AB, Friedman H, Friedman $\mathrm{AH}$, Keir ST, et al. Mutations in IDH1, IDH2, and in the TERT promoter define clinically distinct subgroups of adult malignant gliomas. Oncotarget. 2014; 5(6):1515-1525. doi:10.18632/oncotarget.1765.

42. Killela PJ, Reitman ZJ, Jiao Y, Bettegowda C, Agrawal N, Diaz LA, Jr., Friedman AH, Friedman H, Gallia GL, Giovanella BC, Grollman AP, He TC, He Y, Hruban RH, Jallo GI, Mandahl N, et al. TERT promoter mutations occur frequently in gliomas and a subset of tumors derived from cells with low rates of self-renewal. Proceedings of the National Academy of Sciences of the United States of America. 2013; 110(15):6021-6026.

43. Barbashina V, Salazar P, Holland EC, Rosenblum MK and Ladanyi M. Allelic Losses at 1p36 and 19q13 in Gliomas: Correlation with Histologic Classification, Definition of a 150-kb Minimal Deleted Region on 1p36, and Evaluation of CAMTA1 as a Candidate Tumor Suppressor Gene. Clinical Cancer Research. 2005; 11:1119- 1128.

44. Smith JS, Alderete B, Minn Y, Borell TJ, Perry A, Mohapatra G, Hosek SM, Kimmel D, O'Fallon J, Yates A, Feuerstein BG, Burger PC, Scheithauer BW and Jenkins RB. Localization of common deletion regions on $1 \mathrm{p}$ and $19 \mathrm{q}$ in human gliomas and their association with histological subtype. Oncogene. 1999; 18:4144 - 4152.

45. Tews B, Felsberg J, Hartmann C, Kunitz A, Hahn M, Toedt G, Neben K, Hummerich L, von Deimling A, Reifenberger $\mathrm{G}$ and Lichter P. Identification of novel oligodendrogliomaassociated candidate tumor suppressor genes in $1 \mathrm{p} 36$ and $19 q 13$ using microarray-based expression profiling. International journal of cancer. 2006; 119(4):792-800.

46. Qu M, Olofsson T, Sigurdardottir S, You C, Kalimo H, Nister M, Smits A and Ren ZP. Genetically distinct astrocytic and oligodendroglial components in oligoastrocytomas. Acta neuropathologica. 2007; 113(2):129-136.

47. Wilcox P, Li CC, Lee M, Shivalingam B, Brennan J, Suter CM, Kaufman K, Lum T and Buckland ME. Oligoastrocytomas: throwing the baby out with the bathwater? Acta neuropathologica. 2015; 129(1):147-149.
48. Huse JT, Diamond EL, Wang L and Rosenblum MK. Mixed glioma with molecular features of composite oligodendroglioma and astrocytoma: a true “oligoastrocytoma"? Acta neuropathologica. 2015; 129(1):151-153.

49. Buckner JC, Shaw EG, Pugh SL, Chakravarti A, Gilbert MR, Barger GR, Coons S, Ricci P, Bullard D, Brown PD, Stelzer K, Brachman D, Suh JH, Schultz CJ, Bahary JP, Fisher BJ, et al. Radiation plus Procarbazine, CCNU, and Vincristine in Low-Grade Glioma. The New England journal of medicine. 2016; 374(14):1344-1355.

50. Zhang ZY, Chan AK, Ding XJ, Qin ZY, Hong C.S, Chen LC, Zhang X, Zhao FP, Wang Y, Wang Y, Zhou LF, Zhuang ZP, Ng HK, Yan H, Yao Y and Mao Y. TERT promoter mutations contribute to IDH mutations in predicting differential responses to adjuvant therapies in WHO grade II and III diffuse gliomas. Oncotarget. 2015; 6(28):24871-24883. doi:10.18632/oncotarget.4549.

51. Louis DN, Ohgaki H, Wiestler OD, Cavenee WK, Burger PC, Jouvet A, Scheithauer BW and Kleihues P. The 2007 WHO classification of tumours of the central nervous system. Acta neuropathologica. 2007; 114(2):97-109.

52. Chan AK, Yao Y, Zhang Z, Shi Z, Chen L, Chung NY, Liu JS, Li KK, Chan DT, Poon WS, Wang Y, Zhou L and Ng HK. Combination genetic signature stratifies lower-grade gliomas better than histological grade. Oncotarget. 2015; 6(25):20885-20901.

53. Takami H, Yoshida A, Fukushima S, Arita H, Matsushita Y, Nakamura T, Ohno M, Miyakita Y, Shibui S, Narita $\mathrm{Y}$ and Ichimura K. Revisiting TP53 Mutations and Immunohistochemistry-A Comparative Study in 157 Diffuse Gliomas. Brain pathology. 2015; 25(3):256-265.

54. Zhang RQ, Shi Z, Chen H, Chung NY, Yin Z, Li KK, Chan DT, Poon WS, Wu J, Zhou L, Chan AK, Mao Y and Ng HK. Biomarker-based prognostic stratification of young adult glioblastoma. Oncotarget. 2015; 7(4):5030-5041. doi: 10.18632/oncotarget.5456.

55. Martinho O, Longatto-Filho A, Lambros MB, Martins A, Pinheiro C, Silva A, Pardal F, Amorim J, Mackay A, Milanezi F, Tamber N, Fenwick K, Ashworth A, Reis-Filho JS, Lopes JM and Reis RM. Expression, mutation and copy number analysis of platelet-derived growth factor receptor A (PDGFRA) and its ligand PDGFA in gliomas. British journal of cancer. 2009; 101(6):973-982.

56. Louis DN, Perry A, Reifenberger G, von Deimling A, Figarella-Branger D, Cavenee WK, Ohgaki H, Wiestler OD, Kleihues P and Ellison DW. The 2016 World Health Organization Classification of Tumors of the Central Nervous System: a summary. Acta neuropathologica. 2016; 131(6):803-820. 